\title{
Geography and Chronic Disease: Illustrations from the 1900s and 2000s of the Value and Perspectives of Epidemiology
}

\author{
Thomas C. Erren* and Melissa S. Koch \\ Institute and Policlinic for Occupational Medicine, Environmental Medicine and Prevention Research, University Clinic \\ of Cologne, University of Cologne, Germany
}

\begin{abstract}
This commentary demonstrates that 'Geography and chronic disease' can be associated in unique ways and may point to links in the chain of disease causation in epidemiological studies. Examples from the 1900s and 2000s evince that critical causal insights into disease were gained by utilizing opportunities provided by geography. In the 1940 s, studies that investigated why some cancers were more frequent in specific geographical areas than in others have provided important etiological clues. After comparing disease incidences in Africans versus African-Americans, Kennaway suggested that environmental, rather than genetic or ethnic, factors contribute to hepatic cancers. Further clues into disease etiology were provided through the investigation of "epidemiological islands". One example is the discovery of "new mechanisms for the origin and dissemination of infectious diseases," for which Gajdusek was honored as a colaureate of a Nobel Prize in 1976. As early as the beginning of the 1900s, scientists suggested that studies of cancer development in regions around the Earth's North Pole could be a promising research avenue. Still today, studying cancer in populations that live at extreme latitudes seems to be a promising geographic approach to better understand public health, given that two of the world's most frequent malignancies, namely breast and prostate cancer, are very rare in populations residing north of the Arctic Circle. Overall, this commentary serves as a reminder that the geographically different distribution of chronic diseases across the globe may provide unique opportunities for investigating what protects geographically confined populations against, or what makes them more susceptible to, chronic disease.
\end{abstract}

Keywords: Cancer, causation, chronic disease, environment, epidemiological islands, genes, geography, prevention.

\section{INTRODUCTION}

In this commentary, we will address the following questions: What has been the past and what can be the future role of analyzing links between 'geography and chronic disease' to understand chains of causation that are capable of being broken?

When investigating the theme, we were surprised how little attention is paid - judged by the few papers published in the field - to study options based on geography since they promise substantial gains in medical and epidemiological knowledge.

In our time of great expectations to understand diseases, such as cancer, from molecular viewpoints, it certainly is beneficial to consider some 'observed facts'. According to the 2000 landmark twin study [1], which investigated how environmental and inherited genetic factors contribute to or cause cancers, $0-4$ out of 10 cases of malignancies at 11 different sites were empirically linked to heritable factors. In other words: the robust analyses of data from nearly 45,000 sets of twins in the Nordic countries of Sweden, Denmark and Finland have demonstrated that environmental factors contribute to 60 (prostate) - 100 (cervix uteri, corpus uteri) percent of the risk of sporadic cancers at these 11 locations.

*Address correspondence to this author at the Institute and Policlinic for Occupational Medicine, Environmental Medicine and Prevention Research, University Clinic of Cologne, University of Cologne, Germany; Tel: +49221-4784450; Fax: +49-221-4785119; E-mail: tim.erren@uni-koeln.de
With this - empirical - background, it seems wise to identify environmental determinants of health and disease in man. The editorial [2] which accompanied the aforementioned landmark study (according to Thomson Reuters' web of knowledge cited reference search, as of October 14, 2011, it was cited by 1,219 other scientific articles) concluded that "Geographic differences, trends over time in the risk of cancer, and detailed studies of migrant populations overwhelmingly implicate environmental exposures as major causal factors and often identify the responsible carcinogens (e.g., tobacco, alcohol, radiation, occupational toxins, infections, diet, drugs)." This line of reasoning supports our argument and fits to the objective of this commentary, which is to illustrate the value of looking into not only what determines disease excess but also disease deficits in some geographical regions, but not - or less so - in others.

\section{HISTORICAL EXAMPLES OF THE USE OF GEO- GRAPHY TO UNDERSTAND NON-MALIGNANT CHRONIC DISEASE}

A very visible example where geography helped to identify disease and its probable cause - and possibly a class of disease in humans which is caused by unique infectious agents - is Kuru. In the mid 1900s, an epidemic of an incurable brain disease was observed among a Neolithic people in the highlands of Papua New Guinea. The outbreak appeared to be fuelled by practicing cannibalism at funerals by the Fore people. As a co-recipient, Gajdusek was awarded the 1976 Nobel Prize in Physiology or Medicine for "discoveries concerning new mechanisms for the origin and dissemination of infectious diseases" [3-5]. Work to eluci- 
date the cause [6] of the devastating disease which claimed thousands of lives in the $1960 \mathrm{~s}$ eventually led to the suggestion that this transmissable spongiform encephalopathy [TSE] was caused by prions [7] and is thus related to Creutzfeldt-Jakob-Disease, to which it was already compared in $1957[8,9]$. For his discovery that prions were the infectious agents of TSEs, Prusiner won the 1997 Nobel Prize. Intriguingly, eliminating cannibalism proved to be a highly effective intervention as the devastating disease, which had clustered geographically, disappeared within one generation.

Geography has been used to investigate further neurological disease determinants in isolate island populations. This approach is referred to as "epidemiological islands", "island biogeography" [10] and "island epidemics" [11]. Examples, in which epidemiological isolation has contributed to the description of diseases, and in some cases its causes, include a very high proportion of islanders suffering from achromatopsia on Pingelap [12, 13], an atoll in Micronesia. Apparently, this extremely rare condition of color-blindness is so frequent there due to a devastating typhoon in 1775, which spared only a small number of survivors. Via inbreeding with a typhoon survivor who was a carrier of complete achromatopsia, the prevalence of achromatopsia rose, such that one tenth of today's inhabitants have the condition to a varying degree. Moreover, on Guam, there is a clustering of Lytico-Bodig [14] disease which has still defied the unambiguous identification of its cause(s) [15].

A very recent example of where geography has been used as an option to gain insights into the complicated facets of the links between cause and immunodeficiency disease has been provided through the analyses of SIV (simian immunodeficiency virus) in monkeys on Bioko Island, about $30 \mathrm{~km}$ off the coast of Cameroon [16]. This island has been isolated from Africa for some 10,000 to 12,000 years. And yet, a substantial proportion of the monkeys were found to be sequence-confirmed SIV positives. As a simian origin of HIV has been suggested, these findings could imply that HIV may also be much older than currently estimated. The possible relevance of this finding lies in the fact that, if really so, a long-time co-evolution between HIV and humans would suggest that a short-term attenuation of HIV pathogenicity should not be expected [16].

\section{HISTORICAL EXAMPLES OF THE USE OF GEO- GRAPHY TO UNDERSTAND MALIGNANT CHRO- NIC DISEASE}

In a remarkable contribution to cancer research in the 1940s, Kennaway [17] suggested that the very high incidence of primary cancer of the liver in African populations - when compared with respective incidence data in African-Americans - was not explainable by racial characteristics but could be due to some extrinsic factor. He arrived at this conclusion through the diligent comparison of the "geographical distribution of cancer of the liver in .... the negro in Africa .... [and] the negro in America." His suggestion that ethnic or genetic factors would not be associated with the differential liver cancer occurrence among Africans, on the one hand, and African-Americans, on the other, was subsequently explained by the different geographical distribution of "extrinsic factors", such as hepatitis B infections and the influence of aflatoxin on food products.

Further important contributions to cancer research by using geographical cues have been made in the field of 'arsenic and cancer'. In 1879 [18], inhaled arsenic was recognized as a cause of lung cancer in miners in Saxony. With regard to a carcinogenic potential of ingested arsenic, a series of observations suggested links between arsenic in drinking water and skin cancer in various countries between the 1930s and the 1960s. One of the populations possibly affected by skin cancer via drinking water arsenic was confined to a geographical area on the southwest coast of Taiwan. Remarkably, as evinced by the high prevalence of chronic arsenicism there, a large population of some 100,000 individuals had been exposed to water from artesian wells with high concentrations of arsenic for more than six decades [19]. For more than 40 years, so-called ecological studies in Taiwan played a pivotal role not only for generating hypotheses for cancer etiology but also for the very risk assessments. Taiwan provided the geographical setting for hypothesis-generating and hypothesis-testing because the artesian wells in use since 1900-1910 exposed a large population with significant amounts of arsenic. After initial studies of blackfoot disease, a distinct peripheral vascular disease very prevalent in southwestern Taiwan, and of skin cancer in the 1960s [20] and 1970s [19], very high mortality rates due to internal cancers were reported in 1985 [21], and subsequently shown to be significantly associated with ingestion of high-arsenic artesian well water [22]. Finally, once again, an ecological study in Taiwan demonstrated dose-response relationships between ingested arsenic levels and age-adjusted mortality for a variety of malignant neoplasms, including cancers of the skin, lung, liver, kidney, bladder and prostate [23]. By way of examining the geographical distribution of blackfoot disease [24] in various regions of Taiwan, the researchers first zeroed in on the southwest coast of the island to then link the vascular disease and skin cancer to arsenic from the Earth's crust there. The ecological study results in Taiwan were confirmed by numerous studies in other countries (e.g. Japan, Argentina, Chile), both of ecological design and by observational studies with more methodological weight. Intriguingly, stemming from geographically confined studies, cancer risks from drinking water which contains geogenic arsenic at the old standard of $50 \mu \mathrm{g} /$ liter have been shown to be more than 100 times greater than for any other drinking water contaminant [25].

\section{FUTURE PERSPECTIVES OF THE USE OF GEO- GRAPHY TO PROMOTE CHRONIC DISEASE RE- SEARCH AND PREVENTION}

In 2000, Hoover advocated that "for cancer at many sites there are limited effective options for prevention...unique opportunities to expand our knowledge of risk factors should be exploited regardless of their source" [2]. As we explain in more detail below, systematically pursuing the described 'geography and chronic disease' approach, for instance in Arctic populations, would exemplify taking advantage of such a unique opportunity. 
In the past, having used geographical cues in medicine to better understand chronic disease has certainly been helpful in its own right, as research into respective geographical clusters of disease has contributed to curing them, to alleviating the severity of their symptoms and to the prevention of further outbreaks.

But beyond the possibility of elucidating determinants of health and disease, including cancer, in one geographical setting, investigations in geographically confined areas may allow us to understand what may be prevalent elsewhere in more obscure forms. Note as an example that Gajdusek et al., already in 1957 referred to Kuru as "galloping senescence of the juvenile" [8]: in this vein, this tragic fast paced course of disease may help to understand aging processes which in other geographical areas may be less overt to observe and study. A second example could be neurodegenerative diseases, such as Lytico-Bodig. After all, it seems to provide the unusual combination of what seem to be distinct neurological manifestations elsewhere in the world, namely Amyotrophic Lateral Sclerosis [26], dementia and Parkinsonism. It has been hypothesized that some environmental cause may be responsible for this disease 'entity' [15]. A third example of possible lessons learned from research in one geographical area for people living in other places of the world might be breast and prostate cancer in populations living at the extremes of latitude, namely the Arctic [27-31]. Indeed, it could be very important to find out why malignancies such as breast and prostate cancer, which rank among the most frequent cancers worldwide, are so rare in Arctic populations [32]. This information stems from registries in the Arctic regions of Alaska, Canada, and Greenland which have systematically monitored cancer incidences among some 85,000 up to 110,000 individuals for decades. The case for studies in Arctic populations may be even more compelling as the scientific rationale has been advanced which predicts that hormone-dependent cancers could be rare at the extremes of latitude because of ambient light conditions. More generally, the idea that exposure to visible light may be a contributing factor to, or cause of, internal cancers [31] is gaining some momentum in recent years. But trying to find out whether ubiquitous light can really have such effects in men and women leads to the critical question: How can epidemiology study cancer risks in populations which are differentially exposed to - more or less - light? One idea to examine populations which are exposed to visible light in different ways was to use geography as a means to achieve some light dosimetry ["light dosimetry by geography"] [33]. This is why turning to the Arctic may be a worthwhile step: extended darkness during the day over many months in Arctic winters, it was postulated [27], should lead to higher melatonin levels (melatonin has been called the antithesis of light [34]; light of sufficient intensity suppresses melatonin), which in turn have been implicated as possibly protecting against cancer development. As circumstantial evidence, there is rich data evincing that melatonin may offer some protection $[35,36]$ against all six "hallmarks of cancer' [i.e., self-sufficiency in growth signals; insensitivity to growth-inhibitory signals; evasion of programmed cell death (apoptosis); limitless replicative potential; sustained angiogenesis; tissue invasion and metastasis] suggested by Hanahan and Weinberg in another 2000 landmark paper (according to Thomson
Reuters' web of knowledge cited reference search, as of October 14, 2011, it was cited by 8,903 other scientific articles) [37]. With specific regard to the theme of this commentary, during the celebration of the $4^{\text {th }}$ International Polar Year [38], it has already been suggested that the Arctic could be used as a unique opportunity provided by geography to better understand the promotion of health and the development of diseases, including breast and prostate cancers [32], in humans.

A principal point is in order here as well: clearly, it may be very informative to investigate links with health and disease in stable populations in one geographical setting. Equally clearly, as demonstrated by so-called migrant studies [39], it can be very telling to look diligently on what happens in terms of health and disease in those who move in or out of a geographically confined environments and on what happens to their descending generations. We are likely to see more of these types of observational studies as time goes on due to the growing ease of mobility through technology and globalization.

But this leads to a key methodological point which applies to many migrant studies and beyond. In numerous instances, studies of 'geography and chronic disease' will be - at least in the beginning - of an ecological nature, implying that so-called aggregate, rather than individual data, are considered. In other words: the unit of observation with respect to disease will be groups of people, rather than individuals. In addition, the units of exposure will pertain to geographical areas, rather than to individuals. Such data can lead to inappropriate inferences because associations observed between variables on an aggregate level may not represent biologic effects at the individual level. With this background, therefore, with rare exceptions - such as some of the aforementioned ecological investigations in the field of 'ingested arsenic and cancer' - such ecological studies must remain heuristic or hypothesis-generating. While, as we argue in this commentary - analyses of the variation in cancer occurrence can provide important study leads for promising study locations and populations, to ultimately test the validity of specific hypotheses, in most instances, ecological studies must be followed-up by observational studies with a higher methodological weight. To exemplify, analytical studies which are built upon a host of information at the individual level are required to disentangle the relative roles of environmental and inherited genetic factors in the causation and for the development of cancer as quantified by one starting point of this paper, namely the remarkable twin study of sporadic cancers in Nordic countries.

With further regard to the introduction of this paper, more aspects raised in the New England Journal of Medicine editorial [2] apply to our theme. Certainly, it seems wise, if not imperative, to focus on environmental factors since they determine the vast majority of cancers. Knowledge of what the relevant environmental factors are, could have the potential to help elucidate insights into possible genetic factors, be they facets of protection against or susceptibility to cancer developments, as well. Moreover, if environmental and genetic factors act together, i.e., only when being both present they produce risk or when combined they produce greater risks than the sum of their effects when acting independently, their effects will be eliminated via removal of 
either the environmental or the genetic cause alone. To illustrate this crucial point with an example [40]: prevention of phenylketonuria is possible by low dietary phenylalanine or - in theory - by removing the phenylketonuria gene mutations from populations. Via either preventive approach, 100 percent of cases could be avoided. But this also shows that, while focusing on environmental factors which contribute to disease developments, environmental and genetic factors may appear to be inseparable [40].

As an important basis for determining how and why certain geographic factors and disease patterns correlate, we need to continue to develop tools to facilitate the observation of disease rates. With regard to the example of cancer, the International Agency for Research on Cancer (IARC)'s monograph series on the "cancer incidence in five continents" (CI5) [41] and IARC's new initiative, Globocan [42], which aims to provide cancer incidence estimates at the national level for every country, could prove to be invaluable resources when trying to determine disease patterns based on geographic (i.e. environmental and cultural) settings.

\section{CONCLUSION}

This commentary serves as a reminder that epidemiological studies of both environmental and heritable factors under geographically confined circumstances can be a promising approach in order to understand how diseases develop in different populations - be the populations small or large, or the disease rates more or less. Clearly, this approach is not foolproof and can not provide progress in every setting. But, equally clearly, this genuine epidemiological approach continues to have the potential to contribute new research vistas and to open doors to important discoveries for the health of individuals and populations, where other study designs may not reveal the root of the problem.

\section{ACKNOWLEDGEMENTS}

TCE wishes to acknowledge many years of support from Professor Claus Piekarski who provided the freedom to think.

The authors wish to thank anonymous reviewers for their insightful comments.

\section{CONFLICT OF INTEREST}

The authors declare that they have no competing interests.

\section{REFERENCES}

[1] Lichtenstein P, Holm NV, Verkasalo PK, et al. Environmental and heritable factors in the causation of cancer - analyses of cohorts of twins from Sweden, Denmark, and Finland. N Engl J Med 2000; 343: 78-85.

[2] Hoover RN. Cancer - nature, nurture, or both. N Engl J Med 2000; 343:135-6.

[3] Gajdusek C, Gibbs CJ, Alpers M. Slow-acting virus implicated in kuru. JAMA 1967; 199: 34

[4] Rogers NG, Basnight M, Gibbs CJ, Gajdusek DC. Latent viruses in chimpanzees with experimental kuru. Nature 1967; 216: 446-9.

[5] Gajdusek C, Gibbs CJ JR., Asher DM, David E. Transmission of experimental kuru to the spider monkey (Ateles geoffreyi). Science 1968; 162: 693-4.

[6] Gajdusek C, Gibbs CJ, Alpers M. Experimental transmission of a Kuru-like syndrome to chimpanzees. Nature 1966; 209: 794-6.
[7] Prusiner SB. Novel proteinaceous infectious particles cause scrapie. Science 1982; 216: 136-44.

[8] Gajdusek DC, Zigas V. Degenerative disease of the central nervous system in New Guinea; the endemic occurrence of kuru in the native population. N Engl J Med 1957; 257: 974-8.

[9] Zigas V, Gajdusek DC. Kuru: clinical study of a new syndrome resembling paralysis agitans in natives of the eastern highlands of Australian New Guinea. Med J Aust 1957; 44: 745-54.

[10] Whittaker R. Island Biogeography. Oxford: Oxford University Press; 1999.

[11] Cliff AD, Haggett P, Smallman-Raynor M. Island epidemics. Oxford: Oxford University Press; 2000.

[12] Carr RE, Morton NE, Siegel IM. Pingelap eye disease. Lancet 1970; 2: 667

[13] Carr RE, Morton NE, Siegel IM. Achromatopsia in pingelap islanders. Study of a genetic isolate. Am J Ophthalmol 1971; 72: 746-56.

[14] Cox TA, McDarby JV, Lavine L, Steele JC, Calne DB. A retinopathy on Guam with high prevalence in Lytico-Bodig. Ophthalmology 1989; 96: 1731-5.

[15] Denton GR, Siegrist HG, Jano-Edwards JP. Trace elements in Pandanus (Pandanus tectorius) from a manganese-enriched wetland in Southern Guam: a possible Lytico-Bodig connection? J Toxicol Environ Health A 2009; 72: 574-6.

[16] Worobey M, Telfer P, Souquierre S, et al. Island biogeography reveals the deep history of SIV. Science 2010; 329: 1487.

[17] Kennaway E. Cancer of the liver in the negro in Africa and in America. Cancer Res 1944; 4: 571-7.

[18] Härting FH, Hesse W. Der Lungenkrebs, die Bergkrankheit in den Schneeberger Gruben. Vierteljahrsschrift Gerichtliche Medizin und Öffentliches Gesundheitswesen 1879.

[19] Tseng WP. Effects and dose--response relationships of skin cancer and blackfoot disease with arsenic. Environ Health Perspect 1977; 19: 109-19.

[20] Tseng WP, Chu HM, How SW, Fong JM, Lin CS, Yeh S. Prevalence of skin cancer in an endemic area of chronic arsenicism in Taiwan. J Natl Cancer Inst 1968; 40: 453-63.

[21] Chen CJ, Chuang YC, Lin TM, Wu HY. Malignant neoplasms among residents of a blackfoot disease-endemic area in Taiwan: high-arsenic artesian well water and cancers. Cancer Res 1985; 45: 5895-9.

[22] Chen CJ, Chuang YC, You SL, Lin TM, Wu HY. A retrospective study on malignant neoplasms of bladder, lung and liver in blackfoot disease endemic area in Taiwan. Br J Cancer 1986; 53: 399-405.

[23] Chen CJ, Kuo TL, Wu MM. Arsenic and cancers. Lancet 1988; 1: 414-5.

[24] Chen CJ, Wu, MM, Lee SS, Wang JD, Cheng SH, Wu HY Atherogenicity and carcinogenicity of high-arsenic artesian well water. Multiple risk factors and related malignant neoplasms of blackfoot disease. Arteriosclerosis 1988; 8: 452-60.

[25] Smith AH, Lopipero PA, Bates MN, Steinmaus CM. Public health. Arsenic epidemiology and drinking water standards. Science 2002; 296: $2145-6$.

[26] Snow BJ, Peppard RF, Guttman M, et al. Positron emission tomographic scanning demonstrates a presynaptic dopaminergic lesion in Lytico-Bodig. The amyotrophic lateral sclerosisparkinsonism-dementia complex of Guam. Arch Neurol 1990; 47: 870-4.

[27] Erren TC, Piekarski C. Does winter darkness in the Artic protect against cancer? The melatonin hypothesis revisited. Med Hypotheses 1999; 53: 1-5.

[28] Klassen AC, Platz EA. What can geography tell us about prostate cancer? Am J Prev Med 2006; 30: S7-15.

[29] DeChello LM, Gregorio DI, Samociuk H. Race-specific geography of prostate cancer incidence. Int J Health Geogr 2006; 5: 59.

[30] Erren TC. Low risks at high latitudes: Does the arctic hold clues to prostate cancer? Am J Prev Med 2006; 31: 273.

[31] Erren TC. Does light cause internal cancers? The problem and challenge of an ubiquitous exposure. Neuro Endocrinol Lett 2002; 23 (Suppl 2): 61-70.

[32] Erren TC, Meyer-Rochow VB, Erren M. Health clues from polar regions. Science 2007; 316: 540.

[33] Erren TC, Bjerregaard P, Cocco P, Lerchl A, Verkasalo P. Re: Invited commentary: electromagnetic fields and cancer in railway workers. Am J Epidemiol 2001; 154: 977-9. 
[34] Erren TC, Reiter RJ, Piekarski C. Light, timing of biological rhythms, and chronodisruption in man. Naturwissenschaften 2003; 90: 485-94.

[35] Reiter RJ. Mechanisms of cancer inhibition by melatonin. J Pineal Res 2004; 37: 213-4.

[36] Erren TC. Could visible light contribute to the development of leukaemia and other cancers in children? Med Hypotheses 2005; 64: 864-71.

[37] Hanahan D, Weinberg RA. The hallmarks of cancer. Cell 2000; 100: 57-70.

[38] Leshner AI. Celebrating polar science. Science 2007; 315: 1465.
[39] McCredie M. Cancer epidemiology in migrant populations. Recent Results Cancer Res 1998; 154: 298-305.

[40] Vineis P, Pearce N. Missing heritability in genome-wide association study research. Nat Rev Genet 2010; 11: 589 .

[41] International Agency for Research on Cancer. CI5: Cancer Incidence in Five Continents [Internet]. 2010 [cited 2011 October 14]. Available from: http://ci5.iarc.fr/

[42] International Agency for Research on Cancer. Globocan 2008 [Internet]. 2010 [cited 2011 October 14]. Available from: http://globocan.iarc.fr/

(C) Erren and Koch et al.; Licensee Bentham Open.

This is an open access article licensed under the terms of the Creative Commons Attribution Non-Commercial License (http://creativecommons.org/licenses/by$\mathrm{nc} / 3.0 /$ ) which permits unrestricted, non-commercial use, distribution and reproduction in any medium, provided the work is properly cited. 